\title{
A Study on the Translation of Architecture in Hong Lou Meng
}

\author{
Jiateng Wang \\ University of Shanghai for Science and Technology, China \\ Yiqi Yu \\ University of Shanghai for Science and Technology, China
}

\begin{abstract}
With the development of globalization, cultural exchanges have been widely concerned. And the translation of Chinese literary works has become a trend. Due to the pivotal position of architecture name in literary works, coupled with the rich connotations and communicative function, architectural translation is of great. The building names in the classical novel Hong Lou Meng contained meaningful Chinese cultural connotations, so when translating these names, the literature and culture elements should be taken into consideration. This paper makes a comparative study between Yang Xianyi's and Hawkes' translation on the base of language and culture, picking up some typical buildings to do the case study and exploring the charm of Chinese ancient architecture culture. At last, in the hope of giving some reference to the practical translation process, the paper will give some suggestions in some architecture translation.
\end{abstract}

Index Terms - translation on HLM, language and culture, architecture translation

\section{INTRODUCTION}

Cross cultural communication refers to the communication between native speakers and non-native speakers as well as the communication between the people of different language and cultural backgrounds (Nida, 1993). Since twentieth century, international communication has increasingly frequent, and the special features of the global economic integration require us to pay attention to cross cultural communication (Mark\&Moria, 2005). In 1970s, with the cultural turn on translation studies, translation as a cross-cultural behavior has attracted mounting public attention of translation researchers. Hong Lou Meng, as one of the greatest classical novels, tells a story about decline of a rich and abundant family. The author Cao Xueqin drew a vivid picture of all walks of life in every class in the declining Qing Dynasty. Whether for experts and scholars or the general reader, Hong Lou Meng has a far-reaching influence. In 1970s, English sinologist, professor of Oxford University, David Hawkes began to translate the former 80 chapters of Hong Lou Meng, and the latter 40 chapters were translated by his son-in-law, John Minford. Penguin Books LTD published this translation version, which is called The Story of Stone. At the same era, Chinese translator Yang Xianyi and his British wife Gladys Dai also completed the translation of this masterpiece, which was called Dream of Red Mansions and published by Foreign Language Press.

The two full translation versions of Hong Lou Meng are not only a major event in cultural exchanges between China and English speaking countries, but also an outbreak in literary translation, which promotes the literature translation of Chinese classical novels. Although the investigation of translation study on Hong Lou Meng is a case study, we can gain rich aspirations and resources through the comparison between two languages, literatures and cultures. Moreover, managing them in a scientific method, we can conduct our translation study on the base of our knowledge on language, literature and culture, and meanwhile gain some findings on architecture translation.

\section{TRANSLATION STRATEGIES ON TERMINOLOGIES ARCHITECTURES IN HLM}

The architectures in Hong Lou Meng are created based on Chinese classical gardens. This literary work contains so many buildings ranging from garden yards, pavilions to temples with various styles. The names of those buildings are with different characteristics. Their names follow some rules.

The classical architecture first has a certain type of term in its terminologies. There are two main types: realistic name and abstract name. Realistic names often describe the building's shape, characteristics, usage, functions or its location etc., while abstract names tend to show the emotions or wishes. Unlike realistic names, abstract names pay more attention to its beauty, culture connotation or historical meaning. Except for the realistic and abstract name, there are some special ones that without any regulations but may be the words and phrases from some poems or legend.

According to those different types of name, we should adopt different strategies. Generally speaking, there are three translation methods, transliteration, literal translation and free translation (Baker, 2000). For the realistic name, the translation work would be easy because the building name is understandable thus translator can use responding method to express the meaning. Here are the examples: 
a. 太虚幻境: The Land of Illusion.

This place in the novel refers to a place that not existed in real life, so its translation "the Land of Illusion" adopts literal translation method to illustrate this meaning very well.

b. 省亲别墅: House of Reunion

In Chinese, “省亲”means a married lady goes back home to visit her parents and relatives, and usually with a family reunion meal. Therefore, the free translation "House of Reunion" accurate expresses the function of the building.

However, the abstract names are quiet a tough issue in architecture translation, because the name always has some implicit meanings that we must use related stories or other extra information to help understand what it intends to express. And usually the information we use to understand the name is related to the cultural background. Therefore, the translation should not just be expressiveness but meanwhile pay attention to the culture factors. No matter what kind of translation method is, it can hardly work to keep balance between expressiveness and cultural correctness. Let's see some examples:

c. 有凤来仪: Where Phoenix Alights

This is a special name fails following any rules. These four Chinese characters come from Book of History and refer to the place a noble person stay. But the translation just shows the original meaning of the phrases and lacks its inner meaning. Besides, Phoenix in Chinese means the outstanding woman. Without any further explanation, foreign readers may be confused at the word cluster.

From the examples above we can make a brief conclusion on the problems in architecture translation. First, only the use of one kind of translation method can't do a good translation job. Sometimes we need to integrate two or three methods so as to translate the architecture name correctly and accurately. Second, translators may tend to ignore the hidden meaning when it comes to some abstract names, or fail to keep the culture connotation. Third, the culture gaps between two languages make it sometimes hard to find a corresponding word to express the original language and culture. The most difficult problem in architecture translation is the balance between meaning and culture. The translation pays attention to the meaning may ignore the original text's culture background, and the translation that preserves the culture background may be unreadable to its target readers. Besides, adding explanation is a good way in translation the abstract names, especially in published books but the length should be took into consideration.

\section{ANALYSIS ON ARCHITECTURE TRANSLATION OF HLM}

In Hong Lou Meng, there are a number of different buildings with special names. All the buildings are arranged complicated but well-organized. Yang's translation strategy is different from Hawkes' in the architecture. This chapter will give a brief analysis to the architecture translations of the two famous versions.

\section{A. Architecture Systems in HLM}

There are numerous architecture names in Hong Lou Meng, which are arranged into a complicated but wellorganized system. In addition, every architecture name in Hong Lou Meng has deep hidden meanings and special functions. This paper divides them into three groups: public architecture, residential architecture and religious architecture.

1. Public Architecture

Public architectures are large-scale with good wishes and represent the wealth and high position, which are always used to treat high officials and noble lords or held family parties. Table-2 is some public architecture and its translations.

TABEL-2

\begin{tabular}{|c|c|c|}
\hline Original Names & Yangs & Hawkes \\
\hline 嘉荫堂 & Auspicious Shade Hall & Prospect Hall \\
\hline 晓翠堂 & Morning Emerald Hall Paulownia Room \\
\hline 荣禧堂 & Hall of Glorious Felicity & The Hall of Exalted Felicity \\
\hline 凸碧山庄 & Convex Emerald Hall & Convex Pavilion \\
\hline 大明宫 & the palace of Great Splendour & The Da-Ming Palace \\
\hline 沁芳亭 & Seeping Fragrance Pavilion & Drenched Blossoms Pavilion \\
\hline 梦坡斋 & Mengpo Studio & The Su Dong-Po Rooms \\
\hline 红香戋 & Red Fragrance Farm & The Peony Garden \\
\hline
\end{tabular}

2. Residential Architecture

Residential architecture names are very unique and each one has its own characteristics. With the indication of personalities and destiny, the translation of those names is a great challenge. Table-3 is the Yangs' and Hawkes' translation of residential architecture in this literary work 
TABLE-3

\begin{tabular}{|c|c|c|}
\hline Original name & Yangs & Hawkes \\
\hline 蘅芜院 & Alpinia Park & Nall-Spice Court \\
\hline 㴋湘馆 & Bamboo Lodge House \\
\hline 有凤来仪 & Where the Phoenix Alights & The Phoenix Dance \\
\hline 怡红院 & Happy Red Court & House of Green Delights \\
\hline 缀锦阁 & Variegated Splendour Tower & Painted Chamber \\
\hline 紫菱洲 & Purple Caltrop Isle & Autumn Studio \\
\hline 秋爽斋 & Studio of Autumn Freshness & Smartweed Loggia \\
\hline 蓼风轩 & Smartweed Breeze Cot & Lotus Pavilion \\
\hline 藕香榭 & Pavilion of Scented Lotus & Spring In Winter Room \\
\hline 暖香坞 & Warm Scented Arbour & Sweet-Rice Village \\
\hline 稻香村 & Paddy-Sweet Cottage & Green Bower Hermitage \\
\hline 栊翠庵 & Green Lattice Nunnery & Fort Redwood \\
\hline 紫檀堡 & Sandalwood Castle & The Celestial Fragrance Pavilion \\
\hline 天香楼 & The Pavilion of Heavenly Fragrance & \\
\hline
\end{tabular}

3. Religious Architecture

Religious architectures always relate to traditional culture and show peoples' beliefs. In Hong Lou Meng, those religious buildings are built for funerals, praying activities and ancestor worship. This group of architectures has the most obvious Chinese characteristics. Here are some examples.

TABLE-4

\begin{tabular}{|c|c|c|}
\hline Original Name & Yangs translation & Hawkes \\
\hline 铁槛寺 & Iron Threshold Temple & Water-moon Priory \\
\hline 水月庵 & Water moon Convent & The Temple of Heavenly Master \\
\hline 玉皇庙 & The Jade Emperor's Temple & The temple of Yama \\
\hline 阎王庙 & The temple of the king of hell & The Temple of the Great Lord \\
\hline 元帝庙 & The Temple of Emperor Yuandi & The Convent of the Saviour King \\
\hline 地藏庵 & The Ksitigarbha Nunnery & The Temple of the Water Spirit \\
\hline 水仙庵 & River Goddess Convent & The Taoist Temple of the Lunar \\
\hline 清虚观 & Eoddess \\
\hline 玄真观 & Mysterious Truth Temple & The Dark Truth Monastery \\
\hline
\end{tabular}

Certainly, the above tables are just part of the whole architectures. Considering the large amount of the architecture names, this paper only selects some special and typical architecture names as examples. The translations of those examples are rather different so that we can make a further study.

\section{B. Analysis on the Two English Versions}

As what mentioned above, although the architecture is very complicated, from the three tables above we can see that they are all put in the well-organized system. In different groups, the names are very different both in language and culture, so the analysis should consider from those two aspects.

1. Analysis on Public Architecture

First, from language aspects, Chinese is a language with the emphasis of its sense of beauty, highlighting the connotations instead of the literal meanings. By contrast, English is a language more logical. To understand English, one needs to focus on all the parts of a sentence. However, If other information are not associated to dig its inner meanings, it's difficult to understand Chinese. Just because of such a difference, Chinese architecture can be translated into various English forms.

(1) 嘉荫堂: [Yangs] Auspicious Shade Hall; [Hawkes] Prospect Hall

Analyze the name word by word, “嘉” means good things and “荫” is shade, so Auspicious Shade can be considered as a good translation version. While at most cases, Chinese, unlike English, should consider the meaning from the 
whole context instead of each part of the sentences or phrases. Thus we should combine the two Chinese characters to understand it. “嘉荫” here means good wishes and the hope that family Jia will have a good future under the blessing of the ancestors, so the word "prospect" can better describe such meaning.

(2) 沈芳亭: [Yangs] Seeping Fragrance Pavilion; [Hawkes] Drenched Blossoms

First, the building in the original text is a leisure place for the girls' playing and rest. Because it is built along with the river, the river's name has been adopted. So, this building name indicates its location and beautiful scenery. Yang translates it into "Seeping Fragrance", which can present the beautiful scenery from the smell feelings, and meanwhile meet the demand of expressiveness. As for "Drenched Blossoms", it's more like a metaphor to refer the girls' fate would just like the drenched flowers, although having fair appearance but without good results. Therefore, from the lexical level, Yang's translation is more beautiful but from textual level, maybe Hawkes' is better in the inner meaning.

Then, the name of public architecture, though less related to the theme, contains some cultural items. In the Table-2, there are two culture items, historical person and flower culture.

(3) 梦坡斋: [Yangs] Mengpo Studio; [Hawkes] The Su Dong-Po Rooms

This building is the main stage for Jia Zheng to read books, have meetings with his colleagues etc. Yang's translation is the transliteration. And Hawkes, by using the name a literary giant of Song Dynasty, carried on the Chinese culture in his translation. Su Dongpo is the Hailin scholars in Song Dynasty, but his official career isn't good as his literary work. He was demoted and exiled for several times. Jiazheng is an official of Hanlin Imperial Academy, while at the end of the story, he lost his positions. Thus Hawkes compared Jia Zheng to Su Dongpo to reflect his career as well as the declining of Jia's family.

2. Analysis on Residential Architecture

Residential architectures, especially those for the main characters, are the most important where nearly all the main stories of protagonists happen. And the name of them, to a large extend, are abstract with many quotations.

(4) 有凤来仪[Yangs] Where the Phoenix Alights; [Hawkes] The Phoenix Dance

The original words, as mentioned in Chapter 2, is a phrase from History of Book, but in the text, the author used such an idiom as the architecture names. Without a common term, it's hard to make the readers understand what the phrases refer to. Looking at the two versions we will find the word "where" is the major difference in language structure. Yang Xianyi used the adverbs "where" to remind the readers of a place. Hawkes, however, just capitalize the first letter to inform the reader that this is a proper noun. Both methods are reasonable from language formation, but the adverb of place makes it more accurate.

Besides, the word selection should also be considered into the comparative studies. Different words will influence the whole context at some cases. Here is the example:

(5) 大观园: [Yangs] the Grand View Garden; [Hawkes] Prospect Garden

Both of the versions adopt the word "Garden" to refer to a large private garden. And the difference lies on the former words. Yang basically used literal translation method according to the original words but without losing its grand and spectacular style that sets a variety of landscape in one. Hawkes only used one adjunct word prospect, which belongs to free translation scope. Referring to the Oxford Dictionary, prospect means: (a) wide view of a landscape; (b) picture in the mind or imagination, especially of a future event. Obviously, Hawkes adopted both meanings. For one thing, prospect expresses the grand of the building; for another, this kind of translation has a hint that the name contains the builders' good wishes for this garden, hoping its descendants will keep such a grand style and scenery for a long time. Comparing the two versions, Yangs' is direct and understandable on expressing the splendid features and Hawkes' is better in its extending meaning. But if making a comprehensive view of this book, we can see that “大观园” actually reflects the aristocratic wealth's luxury, but its existence is very short because the existence of the builders is also a flash in the span. Unlike the builders' good wishes to keep the prestige, the family eventually went to declining. Thus the word "prospect" is better than "Grand View".

Then, we can easily find some cultural factors in the building names. Those factors are related to their habitants.

(8) 潚湘馆: [Yang] Bamboo Lodge; [Hawkes] the Naiad's House

The name contains a literary legend. This building is the living place for Lin Daiyu. In Chinese, “潚湘” is the combing name of Xiao River and Xiangjiang River. As a traditional image related to water, the word contains a fresh and beautiful meaning with rich cultural connotation. Meanwhile, it has something to do with the myth of Ehuang and Nvying, the wives of emperor Shun (a legendary monarch in ancient China) who ended their lives in Xiangjiang River after their husband's death. Lin Daiyu, in the novel, was dead when Jia Baoyu married Xue Baochai. So we can deduce that the author compared Lin Daiyu to Ehuang and Nvying, reflecting that her love won't come to a result and at last she will dead for love. In Hawkes' translation, Naiad is a water- nymph in Greek Mythology. Using a nymph that western readers are familiar with to replace the Chinese characters“潇湘” can make readers easily get the obvious characteristics of Lin Daiyu. Yang Xianyi, however, changed it into "bamboo" that fits for the building's features: being surrounded by a bamboo forest. What's more, there is one type of bamboo called mottled bamboo that represents for the story of Ehuang and Nvying. Therefore, from the cultural perspective, Yang cared more about the original text while Hawkes cared for the target language receivers. But what we should note is “潇湘” in Chinese has the same sound as “消香”(usually are used to refer a beautiful girl's death) that indicates the sad ending of Lin Daiyu. So if just translating 
into Naiad, it only indicates the beauty of Lin Daiyu without showing her larmoyant and sentimental personality. Yang's translation can better reflect the novel's connotation, suggesting the protagonist's sentimental, noble and elegant character, representing the Chinese cultural allusions in bamboo, and convey traditional Chinese culture to foreign readers. Considering more dialectic, Yang's version lacks of hints so readers need to understand it through the context or even the explanations. In contrast, Hawkes' translation can make target language receivers understand in a short time because he transferred the context and cultural connotation to make it more convenient and coherence to readers.

Color is another cultural difference between Chinese and English. The most obvious example is the translation of Jia Baoyu's residential place:

(9) 怡红院: [Yang] Happy Red Court; [Hawkes] the House of Green Delight

We can see that the major difference between the two translations is the different translation of color word. The two translators chose a totally different way to deal with the color. Yang preserved it and Hawkes changed it according to their different aims. Red in Chinese culture represents for joyful and happiness while in western country, red is an ominous color. Green, on the contrary, is equivalent to red in English culture.

In the original text, the premier name of this building contained both red and green. Red refers to the crabapple planted in the yard so it represents for the girls. Green is on behalf of the plantain on the other side of the yard, which symbolizes the only boy in the Garden, Jia Baoyu. And “怡” in Chinese means happiness. Jia Baoyu grown up with girls including his sisters and servants, so “怡” in Chinese can be interpret in this way: Jia Baoyu lived happily with all the girls in the Garden. Hawkes, on the contrary, considered red a color represents for celebration and love in China so he changed it to green, the color loved by westerns. Again, Hawkes' translation is target language oriented so that he ignored the culture loads. Yang Xianyi, on the contrary, kept the Chinese culture in his translation aiming at passing the traditional culture to the target language readers.

3. Analysis on Religious Architecture

Religion is a kind of culture itself. So this part, the paper mainly analyzes the translations in a religious cultural view. The architecture terminologies in Hong Lou Meng involved Taoism, Confucianism and Buddhism, which are all equipped with Chinese characteristics. Therefore, the name of those religious architectures contains many features existed in Chinese religions. And the translators, because of different cultural background, use different method to deal with those religious characters.

(10) 地藏庵 [Yangs] the Ksitigarbha Nunnery; [Hawkes] the Convert of the Saviour King

Ksitigarbha is a word in Sanskrit, it is the Sanskrit name for one Chinese Buddha. Saviour King is a character in the Bible. So Hawkes tend to change the obscure Chinese word cluster into the target language that readers familiar with. However, the Saviour King is obvious a Christian word that conflict to the original language. It is a kind of naturalization method. But Hong Lou Meng is a work with vivid Chinese traditional culture. Considering the culture exchanges, it's not a good way to translate the novel with naturalization.

(11)水仙庵: [Yang] River Goddess Convent; [Hawkes] the Temple of the Water Spirit

In Hong Lou Meng, this architecture is a temple worship goddess of the Luo River. According to a fairy tale, Cao Zhi had seen the goodness of daffodil in Luo River in the twelfth month of the lunar year. Afterwards, men of letters often use the Chinese characters “洛神” to refer the daffodil. Therefore, based on such a cultural background, Yang translated it into River Goddess. In western culture, people regard daffodil the demon on water, thus Hawkes used the image "Water Spirit" to describe it.

\section{FINDINGS AND CONCLUSIONS}

\section{A. Findings and Suggestions on the Architecture Translation in HLM}

Considering the above analysis, the paper has found the characteristics of two versions. First, for the public architecture, Yang preferred to translate the literal meaning and left the inner meaning to the readers while Hawkes chosen to translate the connotations. As for the residential architecture and religious architecture, Yang, in order to preserve the original culture, translated the literal meaning and sometimes while added the connotative meanings for the requirements of understanding. And Hawkes tried to equivalent the Chinese cultural factors to western ones. Thus Hawkes' translation destroys the original language.

After the analysis, I have found some problems in some architecture translation in both versions.

The first one is “潇湘馆”. One of the translation used "House” and the other adopted "Lodge", but both words are neither suitable to the original architecture scale. So I would choose the word "Chamber" to replace them and add an explanation on it. Here is my translation:

潇湘馆: Mottled Bamboo Chamber

Mottled bamboo in Chinese is an incarnation of Ehuang and Nvying, beautiful women dead for love in Chinese legend.

The second one: “紫菱洲”. “紫菱” is a kind of caltrop plants, and in English it is usually called water chestnut. Hawkes translated it into "Amaryllis Eyot", but amaryllis is a tall white, pink or red flower shaped like a trumpet that native to South America which has nothing to do with the caltrop plants. Yang translated it into Purple caltrop Isle, but 
there is no purple caltrop in English. Caltrop plants in English only contain Red Caltrop and Water Caltrop. And according to Chapter 37 and Chapter 67 in Hong Lou Meng, water chestnut can best describe it. My translation is as below:

紫菱洲: Water Chestnuts Isle

Thirdly, the translation of “水月庵” is totally literal translation. But actually, water and moon in Chinese have connotative meanings. We often use water and moon to describe things that looks real but actually don't' exist. So “illusion” should be added into the translation. My advised translation of “水月庵” is : “Water-Moon Illusion Priory”

\section{B. Conclusion}

In my opinion, architecture translation is for better communication. Thus it is necessary for target readers know the culture background of original language. With such a purpose, concept translation and literal translation is necessary. And for that architecture with connotations, if the translation can't convey such connotations, we need to adopt free translation to make a explanations.

However, due to inexperience of the author and limitation of space of this paper, this paper certainly has its limitations. First, my analysis of the architecture name translations just picks up some typical ones not all the building names in HLM. Second, the paper is based on the two unabridged translation versions of Hong Lou Meng and ignores those abridged ones. So the study is kind of inadequate and insufficient.

Despite the flaws in this paper, the author believes that this informative and insightful paper provides an inspiration for future researches on architecture translation, especially the ancient architecture in China. Besides, since it is far from perfect, any suggestions are welcome.

\section{REFERENCES}

[1] Baker, M. (2000). In Other Words: A Course Book on Translation. Beijing: Foreign Language Teaching and Research Press.

[2] Hawkes, D. (1973). The story of the Stone Vol.1. London: Penguin Books.

[3] Jabbir, J.K. (2006). Skopos theory: Basic principles and deficiencies. Journal of the College of Arts, 41: 31-41.

[4] Mark, S.\&Moria, C. (2005). Dictionary of Translation Studies. Beijing: Foreign Language Teaching and Education Press.

[5] Newmark, P. (1986). Approaches to Translation. London: Prentice Hall.

[6] Nida, E.A. (1993). Language, Culture and Translating. Shanghai: Shanghai Foreign Language Education Press.

[7] Nord, C. (2001). Translating as a Purposeful Activity: Functionalist Approaches Explained. Shanghai: Shanghai Foreign Language Education Press

[8] Wilss,W. (2001). The Science of Translation: Problems and Methods. Shanghai: Shanghai Foreign Language Education Press.

[9] Yang Xianyi. (2009). A Dream of Red Mansion Vol.1.Beijing: Foreign Language Press.

Jiateng Wang was born in Jinhua, China in 1994. She received her Bachelor of Arts from Zhejiang International Studies University in Hangzhou, China in 2016.

She is currently a graduate in University of Shanghai For Science and Technology, Shanghai, China and majors in Master of Translation and Interpretation. Her research interests include scientific translation and oral interpretation research.

Yiqi Yu was born in Hangzhou, China in 1979. She received her PH.D. degree in English linguistics and literature from Shanghai International Studies University in 2009.

She is currently an associate professor in the College of Foreign Languages, University of Shanghai for Science and Technology, Shanghai, China. Her research interests include translation studies and interpretation studies.

Dr. Yu is a member of Translators Association of China and Shanghai International Studies Association. 